\title{
Ovarian Transitional Cell Carcinoma
}

National Cancer Institute

\section{Source}

National Cancer Institute. Ovarian Transitional Cell Carcinoma. NCI Thesaurus. Code C5240

A carcinoma that arises from the ovary and is characterized by the presence of malignant epithelial cells that resemble malignant urothelial cells. There is no morphologic evidence of a benign or borderline Brenner tumor component present. 